\title{
Long-Term Outcome of Second Allogeneic Hematopoietic Stem Cell Transplantation as Salvage Therapy for Young Patients after Relapse or Graft Failure: Experience at a Single Institution
}

Jean El-Cheikh ${ }^{1 *}$, Roberto Crocchiolo ${ }^{1}$, Alberto Vazquez ${ }^{1}$, Patrick Ladaique ${ }^{2}$, Jean Marie Boher ${ }^{3}$, Sabine Furst ${ }^{1}$, Luca Castagna ${ }^{1}$, Catherine Faucher $^{1}$, Claude Lemarie ${ }^{2,4}$, Boris Calmels ${ }^{2,4}$, Norbert Vey ${ }^{1}$, Mohamad Mohty ${ }^{5}$, Christian Chabannon ${ }^{2,4}$ and Didier Blaise

${ }^{1}$ Unité de Transplantation et de Thérapie Cellulaire (U2T), Département d'Onco-Hématologie, Institut Paoli-Calmettes, Marseille, France

${ }^{2}$ Centre de Thérapie Cellulaire, Institut Paoli-Calmettes, Marseille, France

${ }^{3}$ Département de bio statistique, Institut Paoli-Calmettes, Marseille, France

${ }^{4}$ Inserm, Centre d'Investigations Cliniques en Biothérapie, CIC-B510, France

${ }^{5}$ Département d'hématologie, Hôtel Dieu, Nantes, France

\section{Introduction}

Disease relapse or progression after allogenic transplantation is a severe and life-threatening complication. The median post relapse survival is 3 months (1.6-6) when aggressive intervention is suspended. Although less frequent, graft failure (GF) is also associated with a poor prognosis $[1,2]$.

The optimal treatment strategy for these patients has not yet been established. Although some patients can be re-induced into complete remission (CR) with conventional chemotherapy, only few become long-term survivors [2]. The benefit of donor lymphocyte infusion (DLI) for acute leukaemia is limited and not always possible, especially for patients transplanted with cord blood cells $[1,3,4]$.

The recurrent malignancy or GF is the most frequent indication for second Allogeneic Hematopoietic Cell transplantation (Allo-HCT) [5]. Several studies have shown that a second Allo-HCT improves overall survival after relapse and represents a potential therapeutic option, which may increase the duration of leukaemia-free survival (6-25 months) $[1,2,6]$.

However, this is associated with a high rate of non-relapse mortality (NRM) (24-75\%) [6,7]. These results were obtained from small and heterogeneous series of patients. Furthermore, most studies have not compared the outcome of a second Allo-HCT with other interventions in the modern treatment era [8].

We report our single-centre experience of 22 consecutive patients affected by hematological malignancies who received a second AlloHCT and we analysed transplant outcome after a long term follow up in terms of toxicity and disease outcome.

\section{Patients and Treatments}

Between 1992 and 2009, 22 patients (16 males/6 females) underwent a second Allo-HCT and were treated at the adult allogenic hematopoietic stem cell transplantation program at Institut PaoliCalmettes, the Cancer Research Centre, at Marseille, France. Fourteen patients (64\%) were re-transplanted for relapse, six patients (27\%) were re-transplanted for GF, and two patients had both graft failure and disease progression. Patients' data were collected from a maintained database and by retrospective clinical chart review. The criteria for selection of patients for second transplant was good performance status, young age, availability of stem cells from the same or alternative donor, absence of chronic Graft Versus Host Disease (GVHD) and no alternative possible curative treatment.

The median age at diagnosis of these patients was 34 years (range 17-48 years), 35 years (18-49) at the first allogeneic transplant and 37 years (range 20-49) at the second Allo-SCT.

These patients received their first transplant for treatment of
Acute Myeloid Leukaemia (AML, n=9), Chronic Myeloid Leukaemia (CML, $\mathrm{n}=5$ ) or Acute Lymphoblastic Leukaemia (ALL, $\mathrm{n}=3$ ) or Acute Lymphoblastic Leukaemia Philadelphia positive $(\mathrm{ALL}-\mathrm{PH}+, \mathrm{n}=1)$ or Medullar Aplasia (MA, n=2) and for only one patient with Non Hodgkin Lymphoma (NHL) or Paroxysmal Nocturnal Hemoglobinuria (PNH). Patient characteristics are summarized in Table 1.

Details of disease status and procedures for the first and second transplants appear in Table 2.

Nineteen patients (86\%) had a HLA-identical sibling donor, and three patients (14\%) had a matched unrelated donor (MUD) at the first transplant. Median time between the first and the second Allo-HCT was 12 months (2-134). The median follow up after the first Allo-HCT was

\begin{tabular}{|l|l|}
\hline Characteristics & Value patients (\%) \\
\hline Sex Male/Female & $16 / 6$ \\
\hline Age: median (range) at first Allo-HCT & 35 years (18-49) \\
Age: median (range) at second Allo-HSCT & 37 years (20-49) \\
\hline Diagnosis N (\%) & \\
\hline Acute Myeloblastic Leukemia & $9(41 \%)$ \\
Chronic myeloid leukemia & $5(22 \%)$ \\
Acute lymphoblastic leukemia & $4(18 \%)$ \\
Medullary Aplasia & $2(9 \%)$ \\
Non Hodgkin lymphoma & $1(5 \%)$ \\
paroxysmal nocturnal hemoglobinuria & $1(5 \%)$ \\
\hline Donor origin at the second Allo-HCT & \\
Same donor & $14(64 \%)$ \\
Other donor & $8(36 \%)$ \\
\hline Cause of the second Allo-HCT & $14(64 \%)$ \\
Progression & $6(27 \%)$ \\
Graft Failure & $2(9 \%)$ \\
Graft failure and progression &
\end{tabular}

AML: Acute Myeloid Leukaemia; CR: Complete Remission; ALL: Acute Lymphoid Leukaemia; CML: Chronic Myeloid Leukaemia; TBI: Total Body Irradiation; GVHD: Graft-Versus-Host Disease; PBSC: Peripheral Blood Progenitor Cells; OS: Overall survival; DFS: Disease-Free Survival; M: Male; F: Female; T: Transplant; TRM: Transplant-Related Mortality

Table1: Patients Characteristics

*Corresponding author: Jean El-Cheikh, M.D., Institut Paoli-Calmettes, $232 \mathrm{Bd}$ Ste Marguerite, F-13273 Marseille Cedex 09, France, Tel: +33 491 223823; Fax +33 491 223579; E-mail: elcheikhj@marseille.fnclcc.fr

Received February 24, 2012; Accepted March 17, 2012; Published March 22 2012

Citation: El-Cheikh J, Crocchiolo R, Vazquez A, Ladaique P, Boher JM, et al. (2012) Long-Term Outcome of Second Allogeneic Hematopoietic Stem Cel Transplantation as Salvage Therapy for Young Patients after Relapse or Graft Failure: Experience at a Single Institution. J Transplant Technol Res S2: 005 doi:10.4172/2161-0991.S2-005

Copyright: (c) 2012 El-Cheikh J, et al. This is an open-access article distributed under the terms of the Creative Commons Attribution License, which permits unrestricted use, distribution, and reproduction in any medium, provided the original author and source are credited. 
Citation: El-Cheikh J, Crocchiolo R, Vazquez A, Ladaique P, Boher JM, et al. (2012) Long-Term Outcome of Second Allogeneic Hematopoietic Stem Cell Transplantation as Salvage Therapy for Young Patients after Relapse or Graft Failure: Experience at a Single Institution. J Transplant Technol Res S2: 005. doi:10.4172/2161-0991.S2-005

\begin{tabular}{|c|c|c|}
\hline & First Allo-HCT & Second Allo-HCT \\
\hline $\begin{array}{l}\text { Donor Origin } \\
\text { Related donor } \\
\text { Matched unrelated donor }\end{array}$ & $\begin{array}{l}19(86 \%) \\
3(14 \%)\end{array}$ & $\begin{array}{l}18(82 \%) \\
4(18 \%)\end{array}$ \\
\hline $\begin{array}{l}\text { Stem Cell Source } \\
\text { Peripheral Blood } \\
\text { Bone marrow } \\
\text { Cord Blood }\end{array}$ & $\begin{array}{l}11(50 \%) \\
9(41 \%) \\
2(9 \%)\end{array}$ & $\begin{array}{ll}17 & (77 \%) \\
3 & (14 \%) \\
2 & (9 \%)\end{array}$ \\
\hline $\begin{array}{l}\text { Conditioning intensity } \\
\text { RIC } \\
\text { Myeloablative }\end{array}$ & $\begin{array}{l}12(55 \%) \\
10(45 \%)\end{array}$ & $\begin{array}{ll}19 & (86 \%) \\
3(14 \%)\end{array}$ \\
\hline $\begin{array}{l}\text { Conditioning regimen } \\
\text { Flu-Bu-ATG } \\
\text { Flu-TBI } \\
\text { Flu-Cy-TBI } \\
\text { Flu-Cy-TLI } \\
\text { Flu-Bu-TLI } \\
\text { Cy-Bu } \\
\text { Cy-TBI } \\
\text { OTHERS }\end{array}$ & $\begin{array}{l}8(36 \%) \\
3(14 \%) \\
2(9 \%) \\
0 \\
0 \\
0 \\
5(23 \%) \\
4(36 \%)\end{array}$ & $\begin{array}{l}4(18 \%) \\
5(23 \%) \\
1 \\
2(9 \%) \\
2(9 \%) \\
1 \\
1 \\
6(27 \%)\end{array}$ \\
\hline $\begin{array}{l}\text { GVHD Prophylaxis } \\
\text { CSA } \\
\text { CSA+MMF } \\
\text { CSA+MTX } \\
\text { CSA+MMF+MTX }\end{array}$ & $\begin{array}{l}9(41 \%) \\
5(22 \%) \\
7(32 \%) \\
1(5 \%)\end{array}$ & $\begin{array}{l}8(36 \%) \\
11(50 \%) \\
3(14 \%) \\
0\end{array}$ \\
\hline $\begin{array}{l}\text { Disease Status at Allo-HCT } \\
\text { CR } \\
\text { PROGRESSION } \\
\text { MRD }\end{array}$ & $\begin{array}{l}8(36 \%) \\
11(50 \%) \\
3(14 \%)\end{array}$ & $\begin{array}{l}9(41 \%) \\
11(50 \%) \\
2(9 \%)\end{array}$ \\
\hline $\begin{array}{l}\text { Median of CD34+ } \times 10^{6} / \mathrm{kg} \\
\text { Median of CD3+x106/kg }\end{array}$ & $\begin{array}{l}4.48(0.9-9.6) \\
103(18-436)\end{array}$ & $\begin{array}{l}5.69(1.36-10.57) \\
169(4-628)\end{array}$ \\
\hline $\begin{array}{l}\text { Days with ANC> } 500 \times 10^{9} / 1 \\
\text { Days with platelets }>50 \times 10^{9} / 1\end{array}$ & & $\begin{array}{l}21(8-64) \\
22(1-64)\end{array}$ \\
\hline $\begin{array}{l}\text { Acute GVHD } \\
\text { grade (II-III) } \\
\text { grade (IV) } \\
\text { Chronic GVHD } \\
\text { Limited } \\
\text { Extensive }\end{array}$ & $\begin{array}{l}5(23 \%) \\
0 \\
0\end{array}$ & $\begin{array}{l}5(23 \%) \\
0 \\
3(14 \%) \\
2(9 \%)\end{array}$ \\
\hline
\end{tabular}

RIC: Reduced Intensity Regimen; CR: Complete Remission; MRD: Minima Residual Disease; Flu: Fludarabine; BU: Busulfan; ATG: Anti-tymoglobuline; CY: Cyclophosphamide; TBI: Total Body Irradiation; CSA: Cyclosporin A; MMF: Mycophenolate Mophetyl; MTX: Methotrexate; GVHD: Graft Versus Host Disease

Table 2: Comparison of our cohort 22 patients at the first and second HCT

93 months (17-209) and the median follow up after the second AlloHCT was 80 months range (38-129). At first transplant, 11 patients (50\%) were in progression, 8 patients $(36 \%)$ were in complete remission (CR), and 3 patients (14\%) were in stable or minimal disease after first transplant. As concerns the second Allo-HCT, 19 patients (86\%) received a RIC, with Fludarabine, Busulfan and Anti thymoglobulin (ATG)-based (36\%), or Fludarabine and Total body irradiation (TBI) based $(27 \%)$ or other $(23 \%)$. While only three patients $(14 \%)$ received a myeloablative conditioning regimen. Eighteen patients $(82 \%)$ received a graft from a HLA-identical sibling donor, and 4 (18\%) from a MUD. The same donor was used for the first and second transplant in 14 patients $(64 \%)$; donor gender remained unchanged for 10 patients (45\%) (Table 2)

\section{Statistical analysis}

Data are presented as median and respective ranges. Relapse was defined as first haematological or clinical recurrence at any site. The endpoints analyzed were overall survival (OS), progressionfree survival (PFS) and Transplant-Related Mortality (TRM). Those estimates are provided together with $95 \%$ confidence intervals (CI). (OS) defined as the number of months from the date of second AlloHCT and the date of death; (PFS) defined as the number of months from the date of second Allo-HCT and the date of first observation of relapse or progression; TRM defined as the number of months from the date of second transplant until the date of death occurring in complete remission resulting from transplant-related complications (infections and, or GVHD, or multi organ failure).

The Kaplan-Meier product-limit estimates were used to assess the probability of overall survival (OS) and Progression-free survival (PFS) [9]. The probability of transplant mortality was estimated using the prentice cumulative incidence estimates treating non-transplant related death or relapse as competing events [10]. As part of this analysis, we did not perform any multivariate analysis since the number of patients was relatively small [11].

\section{Outcome after second Allo-HCT}

After second transplant, engraftment occurred in $95 \%$ of cases $(21$ patients): only one patient with cord blood cells had an engraftment failure and received a back up rescue of previously collected autologous stem cells. At the second Allo-HCT the patients received a median of $5.69 \times 10^{6} / \mathrm{Kg}$ of CD 34+ range (1.36-10.57), and $169 \times 10^{6} / \mathrm{Kg}$ of $\mathrm{CD} 3+$ range (4-628). The neutrophil count was higher than $0.5 \mathrm{x}$ $10^{9} / 1$ at a median time of 21 days range (8-64) after transplant, and a platelet count higher than $50 \times 10^{9} / 1$ without transfusions was reached at a median of 22 days range (1-64). The GVHD prophylaxis was not significantly modified between the first and second transplants (Table 2).

One patient presented an acute GVHD with grade I, 5 patients (23\%) had developed acute GVHD grade (II-III), of those 2 patients grade III and none of our patients developed a GVHD grade IV. Five patients (23\%) developed chronic GVHD. Of these, 3 patients (14\%) developed limited chronic GVHD and 2 patients (9\%) an extensive form. Other complications after transplant included severe interstitial pneumonia in one patient; none of patients had a veno-occlusive disease (VOD). Two patients (9\%) died from transplant related causes, one patients because a severe pulmonary infection and one patient because a severe GVHD with multi organ failure. At the last follow up 8 patients $(36 \%)$ were still alive, all of them are in CR and had a performance status (ECOG) of 0 , and five are without any active chronic GVHD requiring steroids.

Twelve patients (55\%) relapsed after the second transplant: 5 AML (23\%), 4 CML (18\%), 2 ALL (9\%) and 1 ALL PH + (5\%). Concerning the 11 patients transplanted with a progressive or refractory disease, 3 of those are alive and with CR, 7 patients died because of disease progression and one patient because of acute GVHD. At the last follow up all those relapsed patients had died. With a median follow-up after the second Allo-HCT of 80 months range (38-129), the 5 and 10 years probability of OS was $36 \% 95 \% \mathrm{CI}(16-56)$ (Figure 1). The progression rate was $28 \%$ IC95 (9.1-46.6) at 5 and 10 years respectively (Figure 2).

At one year after the second Allo-HCT the TRM was 9\% 95\%CI $(0-21)$, and at 1 and 3 years after transplant (Figure 3 ).

\section{Discussion}

We report the results of long-term outcome after salvage therapy with second allo-HCT, in a group of 22 patients consecutively retransplanted at a single-institution program.

The incidence of relapse after Allo-HCT ranges from 10\% to 70\% depending on the original diagnosis and stage of the disease before transplant [12]. CSA withdrawal [12-17], donor lymphocyte infusions (DLI) $[18,19]$ and second transplantation are possible therapeutic 
Citation: El-Cheikh J, Crocchiolo R, Vazquez A, Ladaique P, Boher JM, et al. (2012) Long-Term Outcome of Second Allogeneic Hematopoietic Stem Cell Transplantation as Salvage Therapy for Young Patients after Relapse or Graft Failure: Experience at a Single Institution. J Transplant Technol Res S2: 005. doi:10.4172/2161-0991.S2-005

Page 3 of 5

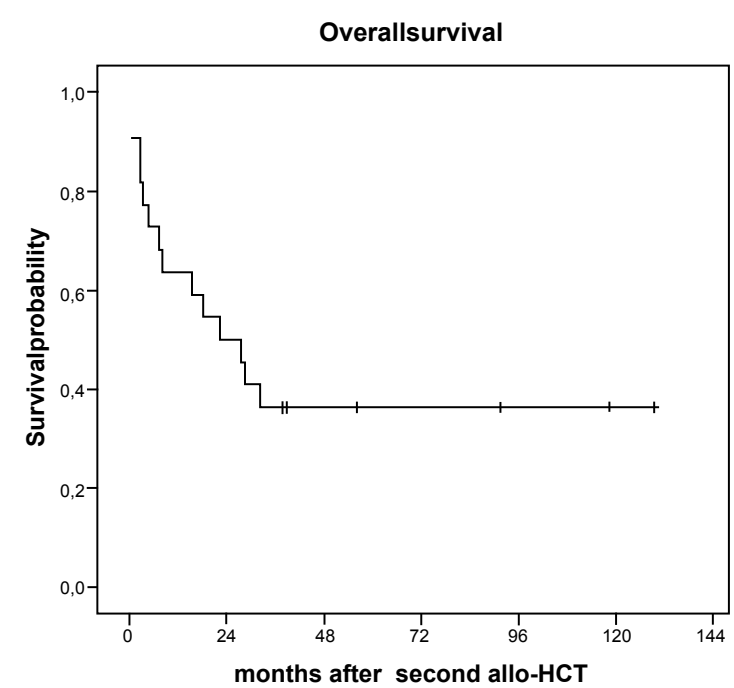

Figure 1: Overall survival OS

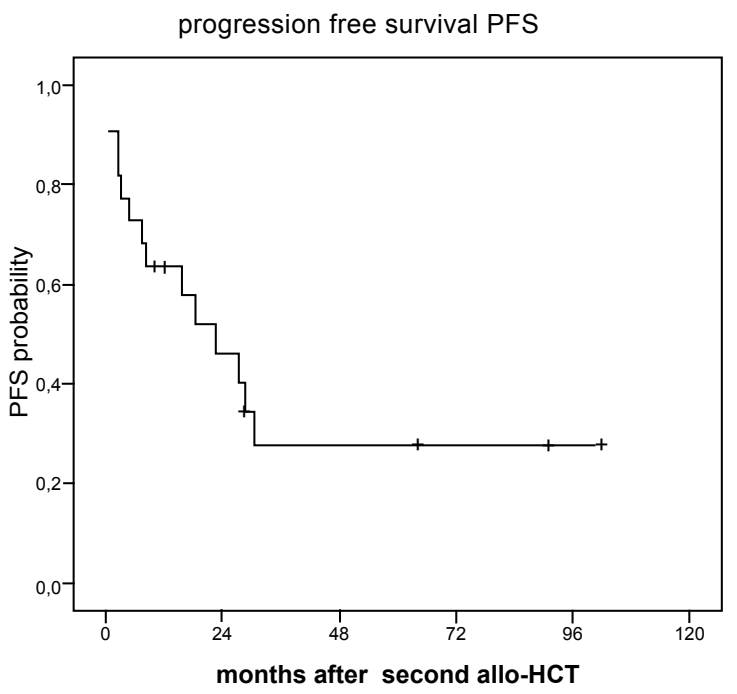

Figure 2: Progression free survival PFS

options [20-22]. In the literature, the results of these different options vary. Therefore, it is difficult to have a clear opinion on the best therapeutic strategy for the relapse of acute or chronic leukaemia after allo-HCT and particularly to determine the exact role of second alloHCT [23-25].

In the literature, the interval between first transplant and relapse lies between 3 and 30 months and the TRM associated with second transplant between $28 \%$ and $50 \%$ [5,6,8,25]. In our study the median interval between first transplant and relapse was 22 months, with a relatively low TRM of 9.1\%. In addition, Russel et al. [24] showed the importance of using allogeneic PBSC as a source of transplantable haematopoietic cells for second transplant; but, in our study, the use of PBSC in only 11 patients precluded any valuable statistical analysis on the impact of this factor. Other authors have also shown the influence on outcome, after a second transplant, of the disease $[8,21,26,27]$; of the interval between first transplant and relapse $[5,8,15,21]$, the occurrence of acute GVHD [21], the presence of chronic GVHD and the occurrence of VOD [28]

Moreover, Falantes et al. [21] and Kishi et al. [27] have observed a better PFS when patients were re-transplanted in CR or Chronic Phase compared with that observed for patients with advanced or refractory disease. In patients with relapsed CML, Arcese et al. [26] also showed the significant influence of patient gender and the use of interferon given for relapse before re-transplantation. An interesting point is that, in some cases, the outcome after the second allo-HCT from the same donor was better than after the first in terms of OS, PFS and TRM.

Better results observed after second transplants with the same donors were similar to the phenomenon observed after infusion of donor lymphocytes, where we could observe a complete chimerism and a specific cytotoxicity against malignant cells accompanying the achievement of CR [17]. In our series, fourteen patients (64\%) received the second Allo-HCT from the same donor; in these patients 4 patients (29\%) are alive and in CR, while the other ten patients died, 9 patients (64\%) because a disease progression and one because a GVHD. In contrast, of the eight patients transplanted with a different donor, four patients (50\%) are still alive and in CR while 4 patients died, 3 patients $(38 \%)$ because a progressive disease and one patient because a severe infection. This significant difference in the incidence of relapse or progression in patients re-transplanted with the same donor (64\%) vs. $(38 \%)$ in patients transplanted from an alternative donor, must be more evaluated $(\mathrm{p}=0.39)$ with $\mathrm{HR}=2.343(0.6-8.5)$. Considering the limited size of our cohort, this aspect is difficult to interpret.

Alternative strategies have been proposed for treating relapse after allo-HCT. Most of these are based on immune modulation enhancing the anti-leukemic effect of donor $\mathrm{T}$ cells. If relapsed patients are still receiving immune suppression, tumour cells could disappear after withdrawal of immune suppression, which unfortunately may also result in uncontrolled GVHD [12,13,18,29].

Recurrent malignancy after transplant may also respond to DLI, with long-lasting remission being reported in more than $50 \%$ of CML patients [17]. In a retrospective single-centre analysis, Elmaagacli et al. [25] examined the outcome of five different therapeutic approaches in $48 \mathrm{CML}$ patients who relapsed after BMT. They observed a 50\% response after abrupt cyclosporine withdrawal, interferon therapy or

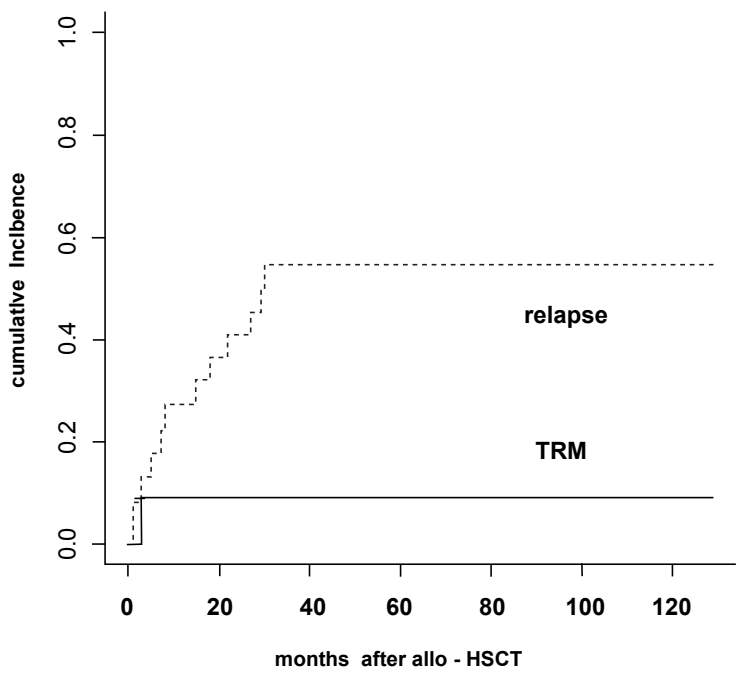

Figure 3: Relapse and transplant related mortality TRM 
Citation: El-Cheikh J, Crocchiolo R, Vazquez A, Ladaique P, Boher JM, et al. (2012) Long-Term Outcome of Second Allogeneic Hematopoietic Stem Cell Transplantation as Salvage Therapy for Young Patients after Relapse or Graft Failure: Experience at a Single Institution. J Transplant Technol Res S2: 005. doi:10.4172/2161-0991.S2-005

second BMT although, somewhat surprisingly, only $14 \%$ of responses were obtained after DLI.

Patients with acute leukaemia in remission and who relapse more than 1 year after a first transplant seem to be good candidates for a second transplant [21]. Of note, our results did not show any difference according to the initial diagnosis, and a second transplant may still be a valuable option for those patients with severe haematological malignancies like AML who experience a late relapse.

The difference in conditioning used before second transplant probably plays a major role [29].

In our study (86\%) received a RIC, that can be explain the low acute GvHD grade II-IV (23\%) and the TRM rate (9\%). Furthermore the relapse rate of $41 \%$ at 2 years was acceptable in those high risk patients relapsing after first allo-HCT. Taking into account all these observations, the poor results of re-transplantations performed for relapse after a first allo-HCT seem to be related to the conditioning regimen toxicity and the advanced phase of the malignancy before conditioning. Nevertheless, second transplantation has been shown to be successful in $20-25 \%$ of patients in several small series $[8,12,16,21,30]$.

In some previously mentioned series, PFS varied from less than $20 \%[19,24,28]$ to more than $35 \%[6,20]$. In our series, after a long median follow up $>6$ years, the 5 and 10 years probability of PFS was $28 \%$, and the probability of relapse at 5 years was $55 \%$. Interestingly the survival and progression curves after second allo-HCT stabilize with time and reach a plateau (Figure 1 and 2).

In conclusion, the limitations of our retrospective single centre study include the small sample size which prevents us from drawing any significant conclusions. Durable disease control was achieved after second allo-HCT and that could offer a good possibility for $1 / 3$ of patients who might be cured. When facing a difficult therapeutic choice, a second transplantation should be considered for young patients who relapse at a long interval after the first allogenic transplant.

\section{References}

1. Arellano ML, Langston A, Winton E, Flowers CR, Waller EK (2007) Treatment of relapsed acute leukemia after allogeneic transplantation: a single center experience. Biol Blood Marrow Transplant 13: 116-123.

2. Oran B, Giralt S, Couriel D, Hosing C, Shpall EJ, et al. (2007) Treatment of $\mathrm{AML}$ and MDS relapsing after reduced-intensity conditioning and allogeneic hematopoietic stem cell transplantation. Leukemia 21: 2540-2544.

3. Collins RH Jr, Shpilberg O, Drobyski WR, Porter DL, Giralt S, et al. (1997) Donor leukocyte infusions in 140 patients with relapsed malignancy after allogeneic bone marrow transplantation. J Clin Oncol 15: 433-444.

4. Dazzi F, Fozza C (2007) Disease relapse after haematopoietic stem cell transplantation: risk factors and treatment. Best Pract Res Clin Haematol 20: 311-327.

5. Savani BN, Mielke S, Reddy N, Goodman S, Jagasia M, et al. (2009) Management of relapse after allo-SCT for AML and the role of second transplantation. Bone Marrow Transplant 44: 769-777.

6. Bosi A, Bacci S, Miniero R, Locatelli F, Laszlo D, et al. (1997) Second allogeneic bone marrow transplantation in acute leukemia: a multicenter study from the Gruppo Italiano Trapianto Di Midollo Osseo (GITMO). Leukemia 11: 420-424.

7. Kishi K, Takahashi S, Gondo H, Shiobara S, Kanamaru A, et al. (1997) Second allogeneic bone marrow transplantation for post-transplant leukemia relapse: results of a survey of 66 cases in 24 Japanese institutes. Bone Marrow Transplant 19: 461-466

8. Hartwig M, Ocheni S, Asenova S, Wiedemann B, Zabelina T, et al. (2009) Second allogeneic stem cell transplantation in myeloid malignancies. Acta Haematol 122: 185-192.

9. Kaplan EL, Meier P (1958) Non-parametric estimation from incomplete observations. J Am Stat Assoc 53: 457-481.
10. Gray RJ (1988) A class of K-sample tests for comparing the cumulative incidence of a competing risk. Ann Stat 16: 1141-1154.

11. Harrell FE Jr, Lee KL, Califf RM, Pryor DB, Rosati RA (1984) Regression modelling strategies for improved prognostic prediction. Stat Med 3: 143-152.

12. Mehta J, Powles R, Treleaven J, Horton C, Meller S, et al. (1997) Outcome of acute leukemia relapsing after bone marrow transplantation: utility of second transplants and adoptive immunotherapy. Bone Marrow Transplant 19: 709719.

13. Higano CS, Brixey M, Bryant EM, Durnam DM, Doney K, et al. (1990) Durable complete remission of acute nonlymphocytic leukemia associated with discontinuation of immunosuppression following relapse after allogeneic bone marrow transplantation. A case report of a probable graft-versus leukemia effect. Transplantation 50: 175-177.

14. Giralt S, Estey E, Albitar M, van Besien K, Rondón G, et al (1997) Engraftment of allogeneic hematopoietic progenitor cells with purine analog-containing chemotherapy: harnessing graft versus-leukemia without myeloablative therapy. Blood 89: 4531-4536.

15. Frassoni F, Barrett AJ, Granena A, Ernst P, Garthon G, et al. (1998) Relapse after allogeneic bone marrow transplantation for acute leukaemia: a survey by the E.B.M.T. of 117 cases. Br J Haematol 70: 317-320.

16. Cullis JO, Schwarer AP, Hughes TP, Hows JM, Franklin I, et al. (1992) Second transplants for patients with chronic myeloid leukaemia in relapse after original transplant with T-depleted donor marrow: feasibility of using busulphan alone for re-conditioning. $\mathrm{Br} \mathrm{J}$ Haematol 80: 33-39.

17. Kumar L (1994) Leukemia: management of relapse after allogeneic bone marrow transplantation. J Clin Oncol 12: 1710-1717.

18. Slavin S, Naparstek E, Nagler A, Ackerstein A, Kapelushnik J, et al. (1995) Allogeneic cell therapy for relapsed leukemia after bone marrow transplantation with donor peripheral blood lymphocytes. Exp Hematol 23: 1553-1562.

19. Kolb HJ, Mittermuller J, Clemm C, Holler E, Ledderose G, et al. (1990) Donor leukocyte transfusions for treatment of recurrent chronic myelogenous leukemia in marrow transplant patients. Blood 76: 2462-2465.

20. Chiang KY, Weisdorf DJ, Davies SM, Enright H, Kersey JH, et al. (1996) Outcome of second bone marrow transplantation following a uniform conditioning regimen as therapy for malignant relapse. Bone Marrow Transplant 17: 39-42.

21. Falantes JF, Carrillo E, Márquez F, Carmona M, Espigado I (2010) Role of second hematopoietic stem cell transplantation in relapsed or refractory hematologic malignancies. Transplant Proc 42: 3225-3227.

22. Thakar MS, Forman SJ (2009) ASH evidence-based guidelines: is there a role for second allogeneic transplant after relapse? Hematology Am Soc Hematol Educ Program 2009: 414-418.

23. Koreth J, Schlenk R, Kopecky KJ, Honda S, Sierra J, et al. (2009) Allogeneic stem cell transplantation for acute myeloid leukemia in first complete remission: systematic review and meta-analysis of prospective clinical trials. JAMA 301 : 2349-2361.

24. Russel JA, Bowen T, Brown C, Luider J, Ruether JD, et al. (1996) Second allogeneic transplants for leukemia using blood instead of bone marrow as source of hematopoietic cells. Bone Marrow Transplant 18: 501-505.

25. Elmaagacli AH, Beelen DW, Schaefer UW (1997) A retrospective single centre study of the outcome of five different therapy approaches in 48 patients with relapse of chronic myelogenous leukemia after allogeneic bone marrow transplantation. Bone Marrow Transplant 20: 1045-1055

26. Arcese W, Goldman JM, D’Arcangelo E, Schattenberg A, Nardi A, et al. (1993) Outcome for patients who relapse after allogeneic bone marrow transplantation for chronic myeloid leukemia. Chronic Leukemia Working Party. European Bone Marrow Transplantation Group. Blood 82: 3211-3219.

27. Kishi K, Takahashi S, Gondo H, Shiobara S, Kanamaru A, et al. (1997) Second allogeneic bone marrow transplantation for post-transplant leukemia relapse: results of a survey of 66 cases in 24 Japanese institutes. Bone Marrow Transplant 19: 461-466.

28. Barrett AJ, Locatelli F, Treleaven JG, Gratwohl A, Szydło R, et al. (1991) Second transplants for leukaemic relapse after bone marrow transplantation: high early mortality but favourable effect of chronic GVHD on continued remission. A report by the EBMT Leukaemia Working Party. Br J Haematol 79: $567-574$ 
Citation: El-Cheikh J, Crocchiolo R, Vazquez A, Ladaique P, Boher JM, et al. (2012) Long-Term Outcome of Second Allogeneic Hematopoietic Stem Cell Transplantation as Salvage Therapy for Young Patients after Relapse or Graft Failure: Experience at a Single Institution. J Transplant Technol Res S2: 005. doi:10.4172/2161-0991.S2-005

Page 5 of 5

29. Pawson R, Potter MN, Theocharous P, Lawler M, Garg M, et al. (2001) Treatment of relapse after allogeneic bone marrow transplantation with reduced intensity conditioning (FLAG +/- Ida) and second allogeneic stem cell transplant. Br J Haematol 115: 622-629.
30. Mrsic M, Horowitz MM, Atkinson K, Biggs JC, Champlin RE, et al. (1992) Second HLA-identical sibling transplants for leukemia recurrence. Bone Marrow Transplant 9: 269-275.

This article was originally published in a special issue, Endothelia Keratoplasty handled by Editor(s). Dr. Jodhbir S Mehta, Singapore Eye Research Institute, (SERI), Singapore; Dr. Saijad Ahmad, Newcastle University, United Kingdom 